\title{
Infecções do trato respiratório inferior pelo vírus sincicial respiratório em crianças hospitalizadas menores de um ano de idade
}

\author{
Respiratory syncytial virus - associated lower respiratory tract infections \\ in hospitalized infants
}

\author{
Cláudio D'Elia', Marilda Mendonça Siqueira ${ }^{2}$, Silvana Augusta Portes ${ }^{2}$ \\ e Clemax Couto Sant'Anna ${ }^{3}$
}

\begin{abstract}
RESUM0
Analisou-se características clínicas e evolutivas em crianças menores de um ano internadas com infecção do trato respiratório inferior por vírus sincicial respiratório (VSR). Feito estudo transversal com 89 lactentes hospitalizados durante as épocas de maior incidência do VSR, em 1997 e 1998, na cidade do Rio de Janeiro. Foram pesquisados antígenos virais, nas secreções de nasofaringe, com anticorpos monoclonais anti-VSR, antiinfluenza A e B e antiparainfluenza tipo 3, por ensaio de imunofluorescência indireta. Formaram-se três grupos: bronquiolite ou bronquite sibilante ( $\mathrm{n}=44)$, pneumonia ( $n=26)$ e bronquiolite e pneumonia $(n=19)$. Houve positividade para o VSR em $42(47,1 \%)$ pacientes. Em 1997 a média de dias de oxigenoterapia foi de 5,2 e em 1998, de 2,5 dias ( $p>0,05$ ). Não houve diferença de apresentação clínica entre os lactentes que apresentaram positividade para o VSR e aqueles cujo resultado foi negativo. Asensibilidade e especificidade da sibilância em relação ao isolamento de VSR foram $85 \%$ e $65 \%$, respectivamente. 0 VSR foi o principal causador de infeções do trato respiratório inferior em lactentes que necessitaram de hospitalização.
\end{abstract}

Palavras-chaves: Infecções respiratórias. Vírus sincicial respiratório. Bronquiolite.

\begin{abstract}
For analysis of clinical features and outcome of hospitalized infants with respiratory syncytial virus lower respiratory tract infection, was carried out. Cross-sectional study with 89 infants, hospitalized in two public hospitals during the 1997 and 1998 RSV seasons, in Rio de Janeiro city. Nasopharyngeal secretions were obtained and specimens processed for viral antigens detection by indirect immunofluorescence assay with the use of anti RSV, antiinfluenza Aand B and anti parainfluenza type 3 monoclonal antibodies. Patients were allocated into three diagnostic groups: bronchiolitis or wheeze bronchitis $(\mathrm{n}=44)$; Pneumonia $(\mathrm{n}=26)$ and bronchiolitis or wheeze bronchitis and pneumonia $(\mathrm{n}=19)$. Positivity for RSV was found in 42 (47.1\%) patients. More days of hospitalization were seen in 1997 in comparison with the follow year ( $p>0.05)$. No clinical differences were found between RSV positive and negative children. The sensitivity and specificity for wheezing concerning the isolation of RSV were, respectively, $85 \%$ and $65 \%$. RSV was the major cause of LRTI in hospitalized infants.
\end{abstract}

Key-words: Respiratory infections. Respiratory syncytial virus. Bronchiolitis.

Nos países em desenvolvimento, os testes laboratoriais para identificação dos vírus causadores de infecções respiratórias agudas (IRA) não são disponíveis na prática. 0 conhecimento do perfil das doenças causadas pelos diversos agentes virais responsáveis pelas IRA poderia permitir a diferenciação destas das infecções bacterianas, evitando muitas vezes, a prescrição desnecessária de antimicrobianos.

0 vírus sincicial respiratório (VSR) é considerado o principal agente causal de infecções do trato respiratório inferior (ITRI)

1. Universidade Federal do Rio de Janeiro, Rio de Janeiro, RJ. 2. Laboratório de Vírus Respiratórios do Instituto Oswaldo Cruz da Fundação Oswaldo Cruz, Rio de janeiro, RJ. 3. Departamento de Pediatria da Faculdade de Medicina da Universidade Federal do Rio de Janeiro, RJ.

Endereço para correspondência: Dr. Clemax Couto Sant'Anna. Rua Barão de Mesquita 459 A, Bloco 2/102, Tijuca, 20540-001 Rio de Janeiro, RJ.

e-mail: clemax@ vetor.com.br

Recebido para publicação em 5/7/2002

Aceito em 10/11/2004 
em lactentes em todo o mundo, embora haja pouca informação a esse respeito nos países em desenvolvimento 2121719 .

A epidemiologia do VSR na cidade do Rio de Janeiro já foi estudada $^{12}$, entretanto, não há publicações regionais relatando 0 comportamento clínico e o desfecho das ITRI pelo VSR em lactentes previamente hígidos, hospitalizados, como no presente estudo. Este trabalho visou também a comparação das características clínicas das ITRI causadas por VSR em dois anos consecutivos.

\section{PACIENTES E MÉTODOS}

Estudo observacional transversal, prospectivo, com crianças menores de 12 meses de idade, internadas nos serviços de pediatria do Hospital Geral de Bonsucesso (HGB) e do Hospital Estadual Rocha Faria ( $\mathrm{HERF}$ ). Ambos são hospitais públicos que atendem principalmente a população de baixa renda.

Foram incluídos pacientes com ITRI para pesquisas virais por imunofluorescência indireta ( IFI). Foram excluídas crianças que apresentavam fatores de risco como: cardiopatias congênitas, imunodeficiências primárias ou adquiridas, displasia broncopulmonar, fibrose cística, história de prematuridade ou que não apresentavam a quantidade mínima de secreções nasofaríngeas para a pesquisa viral.

Definiram-se três subgrupos, considerando-se achados clínicos e radiológicos: I- bronquiolite ( síndrome bronquiolítica); II- pneumonia e III- bronquiolite com pneumonia ${ }^{14}$.

Foram obtidas secreções de nasofaringe (SNF) de 89 lactentes, segundo técnica descrita 5 . As amostras foram coletadas em um período inferior a três dias após a admissão no hospital, nos anos de 1997 e 1998, durante os meses de maio, junho e julho, que correspondem às estações de final de outono e inverno no Rio de Janeiro. Cada espécime foi processado para detecção dos antígenos virais nas células de descamação do trato respiratório por imunufluorescência indireta, utilizando soros imunes policlonais ou anticorpos monoclonais ( antiVSR, antiinfluenza A, antiinfluenza B e antiparainfluenza tipo 3 (PF3), segundo a técnica convencional ${ }^{15}$.

Os registros de idade, diagnóstico, manifestações clínicas e tratamento recebido, foram comparados em relação à identificação ou não do VSR e ao ano de internação (1997 ou 1998).

Realizou-se a descrição das variáveis com distribuição de freqüência para aquelas categóricas e com medidas de tendência central e dispersão para as numéricas. Para a análise de tabelas simples, calculou-se a razão de chances odds ratio (OR).

Para a comparação das médias utilizou-se o teste tde Student e para as proporções o teste do qui-quadrado $\left(\mathrm{x}^{2}\right)$. Foi considerado 0 nível de significância inferior a 0,05 $(p<0,05)$.

\section{RESULTADOS}

Análise geral da amostra. № ano de 1997, foram coletadas amostras de 59 pacientes, correspondendo a 50\% dos 118 lactentes internados com ITRI e no ano de 1998, de
30 pacientes, isto é, 30,3\% dos 99 lactentes internados com ITRI, em ambos os hospitais. Assim, foram incluídos 89 pacientes, 49 do HGB e 40 do HERF, correspondendo a $41 \%$ de todas as internações de crianças menores de 12 meses devido a ITRI durante os meses do estudo. Os diagnósticos destes 89 lactentes, com base em dados clínicos e radiológicos, foram: 44 (49,4\%) com bronquiolite; $26(29,2 \%)$ com pneumonia e 19 $(21,3 \%)$ com bronquiolite e pneumonia. Aidentificação de um ou mais vírus ocorreu em 51/89 (57,3\%) pacientes e os vírus encontrados estão descritos na Tabela 1. A co-infecção com parainfluenza 3 (PF3) foi evidenciada em 9/59 (15,2\%) crianças em 1997. Em 1998, não foi observada qualquer co-infecção.

Tabela 1 - Identificação viral através da IFI em 89 lactentes internados com infeccão do trato respiratório inferior em 1997 e 1998.

\begin{tabular}{|c|c|c|c|c|c|c|}
\hline \multirow[b]{3}{*}{ Vírus } & \multicolumn{4}{|c|}{ Ano } & & \\
\hline & \multicolumn{2}{|c|}{$\begin{array}{c}1997 \\
(\mathrm{n}=59)\end{array}$} & \multicolumn{2}{|c|}{$\begin{array}{c}1998 \\
(\mathrm{n}=30)\end{array}$} & \multicolumn{2}{|c|}{$\begin{array}{c}\text { Total } \\
(\mathrm{n}=89)\end{array}$} \\
\hline & $\overline{\mathrm{n}^{0}}$ & $\%$ & $\overline{\mathrm{n}^{0}}$ & $\%$ & $\mathrm{n}^{0}$ & $\%$ \\
\hline Vírus sincicial respiratório & 28 & 47,5 & 14 & 46.7 & 42 & 47,1 \\
\hline Parainfluenza 3 & 16 & 27,1 & - & - & 16 & 17,9 \\
\hline Influenza A & 2 & 3,4 & - & - & 2 & 2,2 \\
\hline Influenza B & - & - & - & - & - & - \\
\hline
\end{tabular}

IFI - Imunofluorescência indireta

A média de idade dos pacientes foi 2,7 (+/- 2,3) meses e a mediana 2. Havia $44(49,4 \%)$ crianças do sexo masculino e 45 $(50,6 \%)$ do sexo feminino, com relação masculino feminino de 0,98:1. Havia história de um ou mais episódios prévios de sibilância em 15/70 (21,4\%) pacientes. A oxigenoterapia foi prescrita em 49 (55,1\%) lactentes e o tempo de utilização de oxigênio variou de 1 a 28 dias. A internação em unidade de terapia intensiva ocorreu em 20/89 (22,5\%) pacientes. A ventilação mecânica foi indicada em 4/89 (4,5\%) pacientes, destes, 3 pertenciam ao grupo III $\left(x^{2}=7,38 ; p<0,05\right)$. Foram prescritos antimicrobianos a $76 /$ 89 (85,4\%) crianças. Aalimentação no primeiro dia de internação foi suspensa em 41/89 (46,1\%) pacientes, introduzida por sonda naso-gástrica em 2/89 (2,2\%) e 46/89 (51,7\%) receberam a dieta por sucção. 0 tempo total de hospitalização variou de 2 a 43 dias. Não houve evolução para óbito em nenhum dos 89 lactentes.

Análise da identificação viral. A Tabela 2 compara diagnósticos e achados clínicos em casos com e sem detecção de VSR. Entre todos os pacientes VSR positivos 20/42 eram do sexo masculino, com relação masculino feminino de 0,90:1. Contudo, no grupo etário de 0-2 meses a relação foi 2:1 (OR=5,00; IC 95\%: 1,12 - 23,78 ( $p<0,05)$. A sibilância foi verificada em 36/42 $(85,71 \%)$ crianças VSR positivas e em 31/47 $(65,95 \%)$ crianças VSR negativas ( $p>0,05)$. A sensibilidade e a especificidade da sibilância em relação à positividade para VSR foram $85 \%$ e $65 \%$, respectivamente. Não houve diferença de apresentação, do ponto de vista clínico, entre os grupos com e sem detecção de VSR.

0 oxigênio foi prescrito em 21/42 (50\%) lactentes VSR positivos.

A média de dias de internação nos pacientes VSR positivos foi 10,3 $(+/-7,4)$ dias, enquanto nos pacientes VSR negativos foi $9,3(+/-4,9)$ dias $(p>0,05)$. 
Tabela 2- Diagnóstico, achados clínicos e quadro radiológico em pacientes VSR positivos e negativos internados nos HGB e HERF em 1997 e 1998.

\begin{tabular}{lccc}
\hline & $\begin{array}{c}\text { VSR+ } \\
\mathrm{n}=42\end{array}$ & $\begin{array}{c}\text { VSR- } \\
\mathrm{n}=47\end{array}$ & $\mathrm{OR}(95 \% \mathrm{IC})$ \\
\hline $\begin{array}{l}\text { Diagnóstico } \\
\text { bronquiolite }\end{array}$ & 24 & 20 & $1,80(0,71<0 \mathrm{R}<4,60)$ \\
$\quad$ pneumonia & 10 & 16 & $0,61(0,21<0 \mathrm{R}<1,70)$ \\
$\quad$ bronquiolite e pneumonia & 8 & 11 & $0,77(0,24<0 \mathrm{R}<2,42)$ \\
Exame físico & & & \\
$\quad$ cianose & 10 & 17 & $0,53(0,19<0 \mathrm{R}<1,50)$ \\
apnéia & 2 & 3 & $0,73(0,08<0 \mathrm{R}<5,88)$ \\
febre & 22 & 23 & $1,15(0,46<0 \mathrm{R}<2,90)$ \\
sibilos & 36 & 31 & $3,10(0,97<0 \mathrm{R}<10,31)$ \\
estertores & 36 & 39 & $1,23(0,34<0 \mathrm{R}<4,55)$ \\
sintomas das vias aéreas superiores & 24 & 32 & $0,63(0,24<0 \mathrm{R}<1,64)$ \\
esforço respiratório leve & 20 & 21 & $1,13(0,45<0 \mathrm{R}<2,85)$ \\
esforço respiratório moderado/grave & 22 & 26 & $0,89(0,35<0 \mathrm{R}<2,25)$ \\
\hline
\end{tabular}

HGB - Hospital Geral de Bonsucesso; HERF - Hospital Estadual Rocha Faria

Análise comparativa dos anos de 1997 e 1998 em pacientes com detecção de VSR. A comparação entre 1997 e 1998, quanto à ocorrência de manifestações clínicas é mostrada na Tabela 3. Sem considerar um paciente que necessitou de 28 dias de oxigênio, internado em 1998, foi verificada maior média de dias de oxigenoterapia em 1997 (5,2 dias) do que no ano seguinte ( 2,5 dias), porém sem significância estatística ( $\mathrm{t}=1,61$; $\mathrm{p}>0,05)$. Foram admitidos no setor de terapia intensiva sete (16,7\%) pacientes, dos quais seis, durante 0 ano de 1997 (OR=3,55; IC95\%: 0,34 - 88,67) ( $p>0,05)$. Aventilação mecânica foi indicada para tratamento de insuficiência respiratória em 3/42 (7,1\%) pacientes, dois em 1997 e um em 1998. A dieta no

Tabela 3 - Freqüência de manifestações clínicas em crianças internadas com VSR nos anos de 1997 e 1998.

\begin{tabular}{lcccc}
\hline Manifestações Clínicas & $\begin{array}{c}1997 \\
(\mathrm{n}=59)\end{array}$ & $\begin{array}{c}1998 \\
(\mathrm{n}=30)\end{array}$ & $\mathrm{OR}(95 \% \mathrm{IC})$ & $\mathrm{p}$ \\
\hline Cianose & 21 & 6 & $2,27(0,72-7,45)$ & 0,12 \\
Apnéia & 3 & 2 & $0,75(0,09-6,98)$ & 0,76 \\
Febre & 31 & 14 & $1,27(0,48-3,38)$ & 0,60 \\
Sibilos & 42 & 25 & $0,49(0,14-1,69)$ & 0,21 \\
Sintomas das VAS & 34 & 22 & $0,49(0,17-1,43)$ & 0,14 \\
Esforço moderado/grave & $39 *$ & 9 & $4,55(1,59-13,33)$ & 0,001 \\
Vômitos & 16 & 9 & $0,87(0,29-2,58)$ & 0,77 \\
Distensão abdominal & 3 & 1 & $1,55(0,13-41,29)$ & 0,70 \\
Irritabilidade & 15 & 3 & $3,07(0,72-14,05)$ & 0,08 \\
Letargia & 8 & 3 & $1,41(0,30-7,47)$ & 0,63 \\
Convulsão & 7 & 2 & $1,88(0,32-14,35)$ & 0,44 \\
\hline${ }^{*}<<0.05$ & & & &
\end{tabular}

primeiro dia de hospitalização foi suspensa ou administrada por sonda gástrica devido à anormalidade respiratória em 24 (57,1\%) pacientes. Em 1997, isto ocorreu em 17/28 (60,7\%) pacientes e em 1998 em 7/14 (50\%) pacientes ( $p>0,05)$.

Os subgrupos A e B do VSR circularam durante os dois anos; porém, o subgrupo A predominou com percentuais de identificação de 71,4\% (20/28) e 78,6\% (11/14) , em 1997 e 1998, respectivamente.

\section{DISCUSSÃ0}

NNo Rio de Janeiro, foi observada maior incidência de doença causada por VRS nos meses de março, abril e mai $0^{12} \mathrm{e}$ no final do outono e início do invern $0^{18}$, enquanto na região sul do país, o padrão epidemiológico se assemelha mais ao dos países de clima temperado, com picos no inverno e início da primavera. ${ }^{16}$

A percentagem de detecção do VSR nesta amostra foi 47,1\%, sendo semelhante em ambos os anos. 0 fato de terem sido excluídos alguns pacientes que não apresentavam a quantidade mínima de secreção nasal necessária para a pesquisa viral, pode ter superestimado a importância deste agente como causador de ITRI, mas estes valores estão próximos aos encontrados na literatura, em estudos que utilizaram 0 mesmo método de detecção do $\mathrm{VSR}^{7}$. Nos países em desenvolvimento a positividade do isolamento viral varia amplamente, de 27 a 96\%, devido a vários fatores: métodos de identificação do vírus, número de vírus pesquisados, período escolhido para coleta, faixa etária do grupo escolhido ou a reais diferenças das taxas de infecção causada pelo VSR, nos diversos países $^{21}$. No presente trabalho, o VSR correspondeu a 82,3\% dos vírus detectados, contudo, a pesquisa viral não incluiu outros vírus, como 0 adenovírus. Além disso, 0 trabalho foi realizado apenas em crianças menores de 12 meses, e durante 0 período de provável maior incidência de infecção pelo VSR.

Geralmente, após a identificação de um vírus em secreções das vias aéreas superiores, este é considerado 0 agente causal da ITRI ${ }^{3}$. Contudo, não se pode descartar a possibilidade de infecção bacteriana concomitante, em alguns casos4. Há pouca informação a esse respeito nos países em desenvolvimento ${ }^{21}$.

0 percentual de uso de antibióticos iniciados no setor de emergência entre pacientes VSR positivos, foi alto e maior do que 0 encontrado nos pacientes VSR negativos, provavelmente pela imprecisão dos dados clínicosradiológicos em definir a etiologia das ITRI nessa faixa etária3.

Embora se admita que as ITRI bacterianas raramente causem sibilância, já foi observado 0 contrário em países em desenvolvimento ${ }^{22}$. A sibilância ocorreu na maioria dos nossos pacientes VSR positivos, embora com valores baixos de especificidade e de valor preditivo positivo para o diagnóstico de infecção pelo VSR As demais manifestações clínicas não permitiram diferenciação entre o VSR e outros microorganismos causadores de ITRI, daí a importância dos testes de diagnóstico rápido ${ }^{1}$.

Holberg et $\mathrm{al}^{6}$ verificaram que 0 sexo masculino esteve associado a maior risco de ITRI pelo VSR em crianças de 1 a 3 meses. No estudo de Jonhson et al ${ }^{8}$, a relação masculino: feminino encontrada em crianças abaixo de 6 meses foi 2,9:1, contrastando com a de crianças maiores, que foi 1,1:1. A predominância do sexo masculino também foi encontrada em nosso estudo nos pacientes com idades entre 0 e 2 meses, se comparado a distribuição por sexo na faixa de 3 a 12 meses.

A bronquiolite - com ou sem pneumonia - predominou no presente trabalho entre os casos VSR positivos e negativos, portanto, a associação entre esse diagnóstico e a positividade viral não foi aqui demonstrada. Devido ao fato de ter sido 
utilizado um método de deteç̧ão do VSR com boa sensibilidade e por pessoas experientes, na maioria dos pacientes VSR negativos, pertencentes aos grupos bronquiolite e bronquiolite e pneumonia, pode-se admitir que a síndrome bronquiolítica tenha sido causada por outro agente (por exemplo, vírus ou Chlamydia tracomatis) não testado ou não detectado.

O tempo de uso de oxigênio foi empregado, neste estudo, como uma variável de gravidade, já que medidas diretas da saturação de oxigênio do sangue arterial não foram realizadas. Alguns estudos utilizaram outras variáveis, tais como, utilização de oxigênio, internação no CTI, uso de ventilação mecânica, suspensão da dieta e dias de internação ${ }^{91120}$. Os critérios usualmente utilizados para hospitalização consideram a gravidade do paciente ${ }^{720}$. Contudo, em nosso meio, as condições sócioeconômicas desfavoráveis muitas vezes determinam internações prolongadas, não necessariamente relacionadas à gravidade do caso.

Em 1997, aparentemente, as ITRI ocorreram com maior gravidade, a julgar pela maior frequêencia de esforço respiratório moderado a grave encontrada nos pacientes internados. A taxa de internação no CTI poderia ser considerada um parâmetro de gravidade válido. Porém, no presente estudo, não foram aplicados critérios de admissão padronizados.

Em nosso estudo, houve predomínio de isolamento do subgrupo A do VSR em relação ao B nos dois anos de estudo. Tal fato não significa, necessariamente, que 0 subgrupo $\mathrm{A}$ tenha determinado doença mais grave que 0 outro subgrupo, pois seria necessário verificar a distribuição desses subgrupos entre os pacientes VSR positivos tratados ambulatorialmente. Nos pacientes hospitalizados, não foram encontradas diferenças de subgrupos em relação às variáveis clínicas, e demográficas, à semelhança de outros autores ${ }^{1013}$.

0 desfecho foi favorável em todos os casos após o tratamento hospitalar, não sendo observado óbitos nesses pacientes previamente hígidos, à semelhança de Johnson et al ${ }^{8}$.

0 padrão de doença causado pelo VSR nestes dois hospitais do Rio de Janeiro foi semelhante ao descrito nos países desenvolvidos de clima temperado. A grande heterogeneidade de padrões culturais, socioeconômicos e climáticos, assim como as diferenças de prioridades e de recursos disponíveis nas diversas unidades de saúde não permitem que nossos resultados sejam extrapolados para outras regiões do país. Estudos em outras localidades, de preferência incluindo pacientes ambulatoriais, seriam importantes para determinar variações regionais do comportamento clínico e epidemiológico do VSR, já que, em nosso país, há pequena quantidade de trabalhos sobre 0 tema.

\section{REFERÊNCIAS BIBLIOGRÁFICAS}

1. Avendano LF, Larranaga C, Palomino MA, Gaggero A, Montaldo G, Suarez N, Diaz A. Community and hospital acquired respiratory syncytial virus infections in Chile. Pediatric Infectious Diseases Journal 10:564-568, 1991.

2. Cintra OAL, Owa MA, Machado AA, Cervi MC, Figueiredo LTM, Rocha GM, Siqueira MM, Arruda E. Occurrence and severity of infections caused by subgroup Aand B respiratory syncytial virus in children in southeast Brazil. Journal of Medical Virology 65: 408-412, 2001.
3. Cherian T, Simoes EA, Steinhoff MC, Chitra K, John M, Raghupathy P, John TJ. Bronchiolitis in tropical south India. American Journal of Diseases in Children 144:1026-1030, 1990.

4. Degré M. Interaction between viral and bacterial infections in the respiratory tract. Scandinavian Journal of Infectious Diseases 49 ( suppl) : 140-145, 1986.

5. Gardner PS, McQuillin J. Rapid virus diagnosis. Application of immunofluorescence. $2^{\text {nd }}$ edition, Butterworths, London, 1980.

6. Holberg CJ, Wright AL Martinez FD, Ray CG, Taussig LM, Lebowitz MD. Risk factors for respiratory syncytial virus-associated lower respiratory illnesses in the first year of life. American Journal of Epidemiology 133:1135-1151, 1991.

7. Jamjoom GA, al-Semrani, AM, Board A, al-Frayh AR, Artz F, al-Mobaireek KF. Respiratory syncytial virus infection in young children hospitalized with respiratory illness in Riyadh. Journal of Tropical Pediatrics 39:346-349, 1993.

8. Johnson AW, Aderele WI, Osinusi K, Gbadero DA, Fagbami AH, Rotowa NA. Acute bronchiolitis in tropical Africa: a hospital-based perspective in Ibadan, Nigeria. Pediatric Pulmonology 22: 236-247, 1996.

9. Law BJ, De Carvalho V. Respiratory syncytial virus infections in hospitalized Canadian children: regional differences in patient populations and management practices. The Pediatric Investigators Collaborative Network on Infections in Canada. Pediatric Infectious Diseases Journal 12: 659-663, 1993.

10. McIntosh ED, De Silva LM, Oates RK. Clinical severity of respiratory syncytial virus group A and B infection in Sydney, Australia. Pediatrics Infectious Diseases Journal $12: 815-819,1993$.

11. Meert K, Heidemann S, Abella B, Sarnaik A. Does prematurity alter the course of respiratory syncytial virus infection? Critical Care Medicine 18: 1357-1359, 1990.

12. Nascimento JP, Siqueira MM, Sutmoller F, Krawczuk MM, Farias V, Ferreira $\mathrm{V}$, Rodrigues MJ. Longitudinal study of acute respiratory diseases in Rio de Janeiro: occurrence of respiratory viruses during four consecutive years. Revista do Instituto de Medicina Tropical de São Paulo 33: 287-296, 1991.

13. Reese PE, Marchette NJ. Respiratory syncytial virus infection and prevalence of subgroup A and B in Hawaii. Journal of Clinical Microbiology 29: 2614-2615, 1991.

14. Sant'Anna CC, D' Elia C. Bronchiolitis. In: Benguigui Y, Antuñano FJL, Schmunis G, Yunes J ( ed) Respiratory infections in children. Pan American Health Organization, Washington, p. 247-263, 1999.

15. Siqueira MM, Ferreira V, Nascimento JP. RS virus diagnosis: comparison of isolation, immunofluorescence and enzyme immunoassay. Memórias do Instituto Oswaldo Cruz 81: 225-232, 1986.

16. Straliotto SM. Prevalência de vírus respiratórios em pacientes pediátricos em Porto Alegre. Tese de mestrado, Faculdade de Ciências Médicas de Porto Alegre, Porto Alegre, RS, 1995.

17. Stralioto SM, Nestor SM, Siqueira MM. Respiratory syncytial virus groups A and B in Porto Alegre, Brazil, from 1990 to 1995 and 1998. Memórias do Instituto Oswaldo Cruz 96: 155-158, 2001.

18. Sutmoller F, Ferro ZP, Asensi MD, Ferreira V, Mazzei IS, Cunha BL. Etiology of acute respiratory tractinfections among children in a combined community and hospital study in Rio de Janeiro. Clinical Infectious Diseases 20: 854-860, 1995.

19. Vieira SE, Stewien KE, Queiroz DAO, Durigon EL, TöröK TJ, Anderson LJ, Miyao CR, Hein N, Botosso VF, Pahl MM, Gilio AE, Ejzenberg B, Okay Y. Clinical patterns and seasonal trends in respiratory syncytial virus hospitalizations in São Paulo, Brazil. Revista do Instituto de Medicina Tropical de São Paulo 43:119-182, 2001.

20. Wang EE, Law BJ, Stephens D. Pediatric Investigators Collaborative Network on Infections in Canada (PICNIC) prospective study of risk factors and outcomes in patients hospitalized with respiratory syncytial virus lower respiratory tract infection. Journal of Pediatrics 126: 212-219, 1995.

21. Weber MW, Mulholland EK, Greenwood BM. Respiratory syncytial virus infection in tropical and developing countries. Tropical Medicine \& International Health 3: 268-280, 1998.

22. World Health Organization. Bronchodilators and other medications for the treatment of wheeze-associated illnesses in young children. WHO/ARI/ 93.29, Washington, 1993. 